\title{
“Mas Ele Diz que me Ama...": Duplo-Vínculo e Nomeação da Violência Conjugal
}

\author{
Fabrício Lemos Guimarães ${ }^{1}$ \\ Tribunal de Justiça do Distrito Federal e dos Territórios \\ Glaucia Ribeiro Starling Diniz \\ Universidade de Brasilia \\ Fabio Pereira Angelim \\ Superior Tribunal de Justiça
}

\begin{abstract}
RESUMO - O objetivo dessa pesquisa qualitativa foi discutir a aplicação da Teoria do Duplo-Vínculo ao contexto da violência conjugal.Foram consideradostrês critérios de duplo-vínculo: (a) Relacionamento de imenso valor afetivo; (b) Mensagens paradoxais; (c) Impossibilidade de refletir sobre a relação. A estratégia metodológica foi a leitura do livro Mas ele diz que me ama..., aplicação de questionário e reflexão grupal sobre o livro.Participaram da pesquisa 20 mulheres encaminhadas pela justiça. A análise dos títulos atribuídos pelas participantes a sua própria história resultou em quatro categorias que revelaram dimensões da relação duplo-vincular: Ambiguidade de sentimentos; Promessas do parceiro; Constatação da realidade violenta; Perspectiva de nova vida. Essa pesquisa-intervenção facilitou a reflexão das mulheres sobre sua realidade e ofereceu ferramentas para avaliação de riscos da violência.
\end{abstract}

Palavras-chave: violência conjugal, gênero, teoria sistêmica, duplo-vínculo, pesquisa-intervenção

\section{"But He Says He Loves me ...": Double-Bind and Nomination of Marital Violence}

\begin{abstract}
The purpose of this qualitative research was to present and discuss the application of the Double-bind Theory to marital violence. Three double-bind criteria were considered: (a) Relationshipof immense emotional value, (b) Paradoxical messages;(c) Impossibility toreflect about the relationship. The methodological strategy consisted in reading the book But he says he loves me..., answering a questionnaire and participating in a group reflection. Twenty women referred by the Judicial System participated in the research. Analyses of the titles women attributed to their stories generated four categories: Ambiguity offeelings; Partner's promises; Confirmation of the violent reality; Prospect of a new life. This research-intervention facilitated the reflection of women regarding their condition and served as a tool to improve risk assessment.
\end{abstract}

Keywords: marital violence, gender, systemic theory, double-bind; research- intervention.

O padrão é mais ou menos esse: Beijo! Tapa! Beijo! Tapa! Beijo! Tapa! Para cada tapa, ganhamos um beijo, e para cada beijo ganhamos um tapa. Em qual deles escolhemos acreditar? No beijo, é claro. É o que nos mantém ali (Penfold,2006, p. viii-ix).

A dinâmica conjugal violenta leva mulheres a ficarem anestesiadas, ou seja, sem condições de avaliarem o próprio relacionamento e os riscos que correm (Ravazzola, 1997). Elas frequentemente se sentem impotentes e paralisadas diante de sua experiência (Diniz \& Pondaag, 2006; Guimarães, 2009; Ravazzola, 1997).

Nesse contexto, é evidente que elas terão dificuldades em esclarecer os profissionais sobre suas demandas à Justiça. É mais difícil ainda que consigam decidir sozinhas e sem apoio adequado - sobre a continuidade ou não do processo criminal contra seus parceiros (Macedo et al., 2012). Esse empobrecimento da percepção exige compreensão de dimensões da dinâmica conjugal violenta e, consequentemente, do tipo específico de ajuda requerida pelas vítimas (Diniz \& Pondaag, 2006; Pondaag, 2009).

1 Endereço para correspondência: Centro Empresarial Brasil 21, SHS Quadra 06, Bloco I, Sala 215, Asa Sul, Brasília, DF, Brasil. CEP. 70.316-901.E-mail. billguimaraes@yahoo.com.br
As intervenções da Justiça em casos de violência conjugal, no entanto,ainda são marcadas pela incompreensão da demanda das vítimas (Diniz, 2011; Magalhães, 2011; Soares, 2005). Os profissionais tendem a exigir um claro posicionamento dessas mulheres para a permissão da persecução penal do parceiro agressor ou para arquivar o processo judicial (Guimarães, 2009; Magalhães, 2011). Dessa forma, não levam em consideração que elas podem estar aprisionadas a um padrão relacional contraditório e com grande investimento afetivo (Angelim, 2009; Angelim \& Diniz, 2010).

É frequente nas audiências, a exigência de que uma decisão sobre os rumos do processo seja tomada rapidamente. Não é oferecida às mulheres oportunidade mínima de reflexão, explicação sobre o processo e orientação sobre as consequências de sua escolha. Esse procedimento pode fazer com que as mulheres se sintam pressionadas e sem saída, justamente no lugar onde deveriam receber apoio e proteção. Corre-se o risco de induzi-las ao arquivamento do processo (Macedo et al., 2012; Magalhães, 2011).

Resolve-se o processo judicial, mas ignora-se o conflito conjugal. Tampouco, as mulheres adquirirem uma compreensão ampliada de sua experiência (Diniz, 2011). Esse tipo de postura pode resultar no agravamento da situação: elas 
voltam para suas casas fadadas à vivência de repetições dos episódios violentos e descrentes com o Sistema Judiciário (Guimarães, 2009; Magalhães, 2011).

O fato é que mesmo nos casos de crime de lesão corporal, em que atualmente a ação penal é pública incondicionada, ou seja, não depende da representação da mulher para seguir com o processo (STF - ADI 4424/2012) em diversos momentos torna-se necessária uma participação ativa da mulher vítima. Uma questão especialmente importante diz respeito à necessidade ou não de instalação, modificação e/ou mesmo a retirada de Medidas Protetivas de Urgência (MPU). Outras questões igualmente relevantes estão relacionadas à necessidade e/ou mesmo à aceitação para participar em acompanhamento psicossocial, buscar refúgio na casa abrigo, notificar às autoridades possíveis descumprimentos de MPU por parte do parceiro, entre outras medidas que venham a ser necessárias durante o processo.

Mulheres e homens, seja como casais ou ex-casais, acabam retornando à Justiça diversas vezes sem uma resposta efetiva do Estado (Soares, 2005; Saffioti, 1999; Teixeira, 2009). No intuito de evitar a repetição desse padrão, a avaliação de risco realizada pelos profissionais - operadores do direito, equipe psicossocial, entre outros - deve considerar as condições de reflexão de que as mulheres dispõem para perceberem sua situação e elaborarem as queixas de violência (Angelim, 2009; Macedo et al., 2012).

A aplicação da Teoria do Duplo-Vínculo (TDV) aos casos de violência conjugal pode contribuir para a compreensão de dinâmicas relacionais violentas. Tramas do padrão relacional precisam ser desvendadas para que se possa compreender como é difícil e complexa a elaboração de um pedido de ajuda por parte das mulheres. É nosso entendimento que essa teoria pode fornecer ferramentas fundamentais para elucidar parte do "mistério" da permanência e manutenção de um relacionamento violento (Angelim, 2009; Angelim \& Diniz, 2010).

Este artigo tem como objetivo apresentar a aplicação da Teoria do Duplo-Vínculo (TDV) ao contexto da violência conjugal. Inicia com breve discussão sobre o contexto histórico e as principais características dessa teoria, para então tratar das condições de sua aplicação aos relacionamentos conjugais. Apresenta, em seguida, parte dos dados de pesquisa-intervenção que usou essa teoria como uma das ferramentas que pode favorecer a compreensão do fenômeno e a atuação profissional nesses contextos. Finaliza com reflexão sobre a importância da inclusão da TDV para pensar e lidar com situações de violência conjugal.

\section{Teoria do Duplo-Vínculo: Breve contextualização}

A TDV foi apresentada em 1956 por Gregory Bateson, Don Jackson, JayHaley e John Weakland, no artigo "Rumo a uma teoria da esquizofrenia". Esses autores constituíam o grupo de pesquisa que fundou o Mental Research Institute - MRI em Palo Alto, California-EUA, o qual se tornou um dos berços fundamentais de construção de aportes teóricos para a terapia conjugal e familiar de base sistêmica (Angelim
\& Diniz, 2010; Bateson et al., 1956; Carter \& McGoldrick, 1995).

Bateson, Jackson, Haley e Weakland (1956) discutiram o papel da linguagem como processo importante na estruturação da personalidade das pessoas. Lançaram, então, as primeiras ideias sobre a presença de dinâmica duplo-vincular nos relacionamentos familiares. A TDV tornou-se uma nova forma de olhar, entender e intervir na etiologia e manutenção de diversas psicopatologias. Essa teoria se consolidou com forte aporte teórico e de pesquisas na área de saúde mental. Os primeiros estudos foram direcionados às famílias com pacientes diagnosticados com esquizofrenia. Depois, foi aplicada a várias outras psicopatologias (Angelim, 2009).

Terapeutas familiares passaram a investigar e intervir nos padrões de relacionamento ao invés de buscar uma experiência traumática específica como origem dos transtornos psicopatológicos. Saíram de uma visão simplista e linear para uma compreensão sistêmica das relações familiares e da saúde mental de seus membros (Angelim \& Diniz, 2010).

Influenciados pelo trabalho de Bateson et al. (1956), Watzlawick, Beavin e Jackson (1967/1995) começaram a perceber algumas dinâmicas comuns em diversas famílias com pacientes esquizofrênicos em suas pesquisas. Essas características foram consideradas as condições de duplovínculo. Os autores perceberam que determinadas condições relacionais configuravam experiências constantes, que precisavam ser vivenciadas diversas vezes para desencadear um transtorno.

Watzlawick et al. (1967/1995) descreveram cinco critérios específicos para avaliar se uma relação poderia ser considerada como duplo-vincular: (a) Presença de duas ou mais pessoas em uma relação intensa e de elevado valor de sobrevivência; (b) Prevalência de mensagens paradoxais, em que a pessoa afirma algo (p. ex.: "você pode sair com suas amigas") e comunica algo contraditório sobre a própria afirmação (p. ex.: brigar pelo fato de a mulher estar se arrumando para sair com as amigas), ou seja, as duas mensagens excluem-se mutuamente e são apresentadas em níveis comunicacionais diferentes; (c) $\mathrm{O} / \mathrm{a}$ receptor/a da mensagem fica impedido/a de refletir e de sair do padrão interacional; (d) Quando o padrão de DV é duradouro, transforma-se em expectativa autônoma e não requer reforço posterior para se perpetuar; e (e) O comportamento paradoxal imposto pela dupla vinculação é, por sua vez, uma dupla vinculação e isso redunda em um padrão de comunicação que perpetua a si mesmo.

A aplicação desses critérios da TDV aos casos de violência conjugal pode ajudar a identificar elementos dessa dinâmica conjugal e os riscos presentes nesse tipo de relacionamento. Essa avaliação de risco pode ser realizada pelos profissionais e mesmo pelas pessoas envolvidas na relação: mulheres, homens, familiares, amigos e comunidade. Neste trabalho, partimos do pressuposto de que a identificação desses critérios pode contribuir para criar condições para que mulheres possam refletir sobre o relacionamento e fazer uma escolha consciente sobre manter ou não o vínculo conjugal. 


\section{Teoria do Duplo-Vínculo e Violência Conjugal}

Uma relação conjugal violenta pode ser considerada duplo-vincular a partir da constatação da presença de pelo menos três das condições citadas anteriormente: (a) Uma pessoa de valor afetivo importante e com valor de sobrevivência; (b) Presença de mensagens paradoxais; e (c) Impossibilidade de refletir sobre ou sair da relação (Angelim, 2009; Angelim \& Diniz, 2010). Cada uma dessas condições será problematizada a seguir.

\section{$1^{\text {a }}$ condição: Uma Pessoa de Valor Afetivo Importante/ Valor de Sobrevivência}

Essa condição é baseada no valor de sobrevivência que uma pessoa dá à outra. É estruturada na crença de não conseguir sobreviver sem a presença do/a cônjuge, mesmo quando a relação fica bastante adversa - como no caso da presença de violência conjugal. Há uma forte dependência e esse valor afetivo favorece a instalação de dinâmica de submissão e de necessidade do reconhecimento da pessoa amada (Watzlawick et al., 1967/1995).

A vivência de afeto, de amor em relação ao/à parceiro/a, é importante para o relacionamento e para a construção da própria identidade (McGoldrick,1994). A ideologia do patriarcado deturpa esse ideal de amor preconizado pela sociedade. Impõe que as mulheres vivam em função dos cônjuges, mesmo que seja em detrimento de suas necessidades e desejos pessoais. Prevalece, então, a ideia paradoxal de que as mulheres devem esquecer de si mesmas e privilegiar o cuidado com o parceiro e os filhos. Nesse contexto, tendem a se sentir obrigadas a suportar tudo inclusive a violência - para manter sua família (Angelim, 2009; Diniz \& Pondaag, 2006; Pondaag, 2009).

A instalação desse valor de sobrevivência também está relacionada ao valor que a sociedade atribui aos papéis sociais de marido e esposa. Há, inclusive, um status social diferenciado para homens e mulheres casados. Fica a ideia de que o casamento promove maior serenidade, amadurecimento e respeito. Essa valorização social pode dificultar pensar em outra possibilidade senão a de continuar na relação conjugal.

Os indícios de um relacionamento marcado pelo valor de sobrevivência podem ser identificados nas justificativas para a manutenção da relação violenta. Geralmente são expressas pelas vítimas em audiência e nos pedidos de arquivamento do processo judicial. Elas enfatizam o papel de pai e trabalhador do parceiro agressor. Isso mostra a prioridade da manutenção da família e a valorização do papel do homem em detrimento da sua própria integridade e sua saúde (Angelim, 2009; Angelim \& Diniz, 2010).

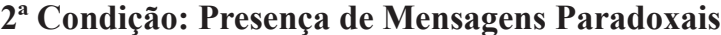

A violência é por si só uma contradição ao amor, que é o sentimento básico esperado socialmente em uma relação conjugal (Diniz, 2011). Os ideais de amor são reforçados a todo o momento pela sociedade, por meio de filmes, novelas, contos de fadas, músicas, transmissão transgeracional etc. A presença do amor implica, no imaginário social, em aceitação incondicional das características do/a parceiro/a, em dedicação às suas necessidades e exigências, em abnegação, sacrifício e cuidado.

Saffioti (1999) argumenta que ainda se constitui uma utopia esperar que todos os seres humanos amem uns aos outros, mas é essencial o respeito. $\mathrm{O}$ amor depende também da convivência e "não constitui uma obrigação, mesmo porque o amor não nasce da imposição. Respeitar o outro, sim, constitui um dever da/o cidadã/ão, seja este outro mulher, negro, pobre" (p. 85). Mesmo que não haja amor, a violência constitui um paradoxo em relação ao respeito ao/à outro/a e à dignidade humana.

O fato é que as expectativas sociais em torno dos papéis de mulher, mãe e esposa são perpassadas por mensagens contraditórias. Mulheres devem tolerar tudo, inclusive as agressões, para serem/sentirem-se legitimadas e reconhecidas como sujeito feminino. Angelim e Diniz (2010) defendem que "reconhecer os paradoxos presentes nesse processo de construção identitária e sua ancoragem nas expectativas e papéis de gênero socialmente construídos constitui um desafio para todas as mulheres, mas em especial, para mulheres vítimas de violência” (p. 404).

Serão discutidos a seguir três indícios importantes da força das mensagens paradoxais no contexto da violência: a interpretação da violência; as justificativas e a ambiguidade de sentimento. $\mathrm{O}$ primeiro indício ocorre quando a mulher interpreta o episódio de violência como demonstração de afeto. Essa contradição tem o ciúme como principal elemento. Ao percebê-lo como expressão intensa de amor, ela pode assumir posição compreensiva e paradoxal: valoriza o "sofrimento" do parceiro manifesto pelo ciúme; busca mudar e restringir seus próprios comportamentos para não "provocar" ira; e não se permite sentir a dor das agressões.

O ciúme excessivo não tem como base o amor, mas o sentimento de insegurança, de controle e de posse. A mulher pode também ver o seu parceiro como um doente, como um sofredor que precisa ser cuidado. Essa interpretação pode aprisioná-la ainda mais à relação. A separação pode ser vista como sinônimo de abandono, e a mulherpode sentir-se extremamente culpada por isso (Guimarães, 2009).

As justificativas utilizadas pelas mulheres para explicar e minimizar a violência e suas consequências constituem outros indícios da existência de mensagens paradoxais. Elas explicam as agressões como gestos involuntários ou atos reflexos do parceiro. Atribuem a violência a fatores externos, geralmente ao álcool e ao uso de outras drogas. As violências verbais ou empurrões são vistos como atitudes do parceiro para evitar agressões maiores. Essa é uma das consequências mais graves da violência - o fato de que a vítima passa a justificar a violência que sofre (Guimarães, 2009).

$\mathrm{O}$ terceiro indício de um relacionamento marcado por mensagens paradoxais é a ambivalência de sentimentos. Mulheres em situação de violência conjugal tendem a se sentirem extremamente confusas - não sabem se amam ou odeiam o parceiro agressor; se têm afeto ou raiva, se têm compaixão ou revolta. Essa ambivalência fica evidente nos pedidos de arquivamento de processos judiciais; na disposição para cuidar do parceiro agressor. Essa ambiguidade também aparece no ciclo de violência, em que se instala um padrão de 
diversos términos e retornos à relação. Terminar e reconciliar a conjugalidade evidencia a coexistência da expectativa de sair da relação e a esperança de mudança na sua dinâmica (Guimarães, 2009; Walker, 1999).

Essa dinâmica relacional torna ambos os cônjuges prisioneiros do paradoxo entre amor e agressão. Tanto homens como mulheres permanecem presos a essa dinâmica. A pressão social e as cobranças recaem injusta e exclusivamente sobre a mulher por ser a pessoa em condição de desvantagem e marcada pelas desigualdades de gênero. As mulheres podem se sentir obrigadas a resolverem sozinhas todos os problemas familiares. Esse dilema as coloca diante de outro paradoxo: "ficar para resolver ou sair para resolver? Elas ficam presas em uma armadilha: se ficam são criticadas, acusadas de gostar de apanhar; se saem, são vistas como fracas, e acusadas de provocarem a ruptura familiar" (Guimarães, 2009, p. 69).

A ambivalência de sentimento atinge seu extremo quando ocorre o paradoxo entre amor e ódio. A dinâmica violenta pode aumentar de intensidade e de frequência até atingir um fim trágico: a morte de um dos cônjuges, na grande maioria dos casos da mulher. A tendência é ocorrer o feminicídio (Krug, Dahlberg, Mercy, Zwi,\& Lozano, 2002; Waiselfisz, 2012) ou o homicídio da mulher seguido de suicídio do homem (Aguiar, 2009; Angelim, 2009; Macedo, 2013; Teixeira, 2009).

A dinâmica duplo-vincular presente nessa situação não permite alternativas fora da relação, senão a morte dos cônjuges (Angelim \& Diniz, 2010). Ambos ficam aprisionados a esse padrão de relacionamento. O livro Nunca você sem mim: Homicidas-suicidas nas relações afetivoconjugais, de Analba Teixeira (2009), ilustra bem como a conjugalidade violenta pode evoluir até o desfecho trágico de um homicídio-suicídio. Outro estudo - Mapa da Violência no Brasil - de Waiselfisz (2012) revela que 91 mil mulheres foram assassinadas nos últimos 30 anos, sendo mais de 43 mil na última década (aumento de $216 \%$ nesse período). Entre essas, quase $68,8 \%$ foram mortas dentro de casa e, se considerarmos mulheres na faixa etária de 20 a 49 anos, $65 \%$ foram executadas pelos parceiros ou ex-parceiros. É alarmante o índice de letalidade da violência doméstica e familiar no país.

\section{$3^{0}$ condição: Impossibilidade de Refletir sobre a Relação}

A terceira condição do duplo-vínculo nas relações conjugais violentas é marcada pela impossibilidade de reflexão sobre a sua própria dinâmica. Simone de Beauvoir (1967) defende que existe uma estereotipia do comportamento feminino, em que as mulheres ficam subjetivamente dependentes do lócus conjugal e familiar. Essa expectativa social por si só é um fator que dificulta a reflexão das mulheres sobre sua condição subjetiva (Angelim, 2009; Guimarães, 2009).

Em uma dimensão relacional, o ciclo da violência também dificulta a reflexão sobre a situação da relação violenta (Walker, 1999). A repetição do ciclo faz com que a mulher se adapte aos altos e baixos da vivência conjugal.
Diante do medo, a vítima faz todo um movimento para eliminar questões associadas à percepção da violência: falta de autonomia pessoal, agressividade do parceiro, alterações do humor, rotinas, divisão de trabalhos domésticos, ciúmes etc. Mulheres esperam que essa atitude possa mudar o comportamento do companheiro ou pelo menos evitar novas agressões (Saffioti, 1999).

Esse processo pode levar a um estado de hiper vigilância e de desamparo aprendido (Angelim, 2009; Walker, 1999). Lamentavelmente, a tendência é a retomadadas fases mais violentas do ciclo, o que faz com que os momentos de tranquilidade fiquem cada vez mais curtos e raros (Guimarães, 2009; Soares, 2005; Walker, 1999).

O uso do silêncio e do segredo também dificulta a reflexão sobre a relação (Diniz \& Pondaag, 2006; Pondaag, 2009). As mulheres podem ter dificuldade para verbalizar as experiências de agressão e nomeá-las como violência. Tendem, assim, a utilizar o silêncio, o segredo e o não dito como estratégia de enfrentamento (Pondaag, 2009).

A violência é um fenômeno muitas vezes inesperado e aterrorizante. Surge daí essa dificuldade em nomeá-la. No contexto da dinâmica conjugal violenta, os envolvidos não percebem os atos como realmente acontecem e ficam anestesiados - não sentem plenamente as suas consequências (Ravazzola, 1997). A autora defende que "não vemos as coisas para as quais não encontramos nomes. Tampouco vemos que não as vemos. Acreditamos então sem esforço que elas não existem. O efeito do 'duplo-cego' (...) é poderoso" (p. 92). A anestesia acontece com tanto êxito que o mal-estar deixa de ser sentido, o que ajuda a entender porque algumas mulheres contam os seus dramas sorrindo, mesmo quando a violência é extrema (Ravazzola, 1997).

A instalação das anestesias na dinâmica conjugal e o uso do silêncio e do segredo como estratégias de sobrevivência revelam, portanto, outro paradoxo: apesar da dor e do sofrimento causado pela violência, a mulher fica impedida de nomeá-la (Diniz \& Pondaag, 2006; Guimarães, 2009). A dificuldade em falar sobre a violência é um fator que atrapalha ou impede a formulação de um pedido de ajuda efetivo. Essa estratégia de sobrevivência contribui para a insatisfação e sofrimento da mulher na relação conjugal e cria obstáculos para a construção de sua autonomia (Pondaag, 2009).

O isolamento social da família também dificulta ou impossibilita a reflexão sobre a relação (Angelim \& Diniz, 2010; Soares, 2005). Esse isolamento é muito comum em famílias em situação de violência e ocorre quando a vítima perde ou diminui significativamente o contato com seus parentes, amigos e comunidade. O parceiro geralmente tenta impedir de todas as maneiras que a mulher estude, trabalhe e circule livremente (Alves \& Diniz, 2005; Soares, 2005). $\mathrm{O}$ isolamento atua como uma consequência da violência e, ao mesmo tempo,como um fator de risco - contribui para a formação de um círculo vicioso e favorece a sua perpetuação (Guimarães, 2009).

Uma análise detalhada desses critérios carrega o potencial de revelar o quanto um relacionamento violento pode estar alicerçado em padrões de duplo-vínculo. Essa análise deve ser feita à luz de uma perspectiva de gênero, no intuito de evitar "condicionar o tipo de relação afetiva entre agressor e 
vítima e naturalizar algumas das contradições vividas pelas mulheres" (Angelim \& Diniz, 2010, p. 403).

\section{Aplicação da Teoria do Duplo-vínculo a Relações Conjugais Violentas}

Várias pesquisas (Hamilton \& Armstrong, 2009; Mahmoud, 2003) defendem a importância de se discutir a dinâmica duplo-vincular nas relações sociais, familiares e conjugais. Poucos estudos relacionam TDV e violência conjugal (Knickmeyer, Levitt, Horne, \& Bayer, 2004). Esses autores discutiram como algumas questões religiosas têm características duplo-vinculares e aprisionam as mulheres à dinâmica conjugal violenta.

Por mais que os paradoxos possam estar presentes em todas as relações conjugais, defendemos a necessidade de ampliar a compreensão de uma dinâmica relacional violenta. Os critérios discutidos acima vão além das mensagens paradoxais e configuram uma dimensão estruturante da relação violenta. Por estarem arraigados à dinâmica conjugal, a mera constatação do episódio de violência não é suficiente para compreender, intervir e mudar um padrão relacional permeado pelo duplo-vínculo.

É preciso promover ou aprimorar a capacidade de reflexão dos/as envolvidos/as na dinâmica conjugal violenta (Angelim, 2009; Macedo, 2013). Esses recursos de reflexão estabelecem limites para o próprio significado da experiência violenta para a vítima. Podem ajudá-la a reconhecer e a superar o padrão de relacionamento duplo-vincular violento e ampliar sua capacidade de avaliar os riscos da violência. Por fim, podem imprimir mais clareza à sua denúncia junto ao Estado (Angelim, 2009; Angelim \& Diniz, 2010).

Uma mulher inserida em uma dinâmica duplo-vincular está em situação vulnerável. A probabilidade de seu retorno para o relacionamento é alta - mesmo que ele seja permeado pela violência, que não tenha nenhuma perspectiva de mudança, e, inclusive, após a mulher ter buscado ajuda de familiares, amigos e da Justiça. Esse processo leva a um desgaste e descrédito junto à sua rede de apoio familiar e institucional (Angelim \& Diniz, 2010). Os autores enfatizam que:

enredada num padrão de relacionamento duplo-vincular a vítima e o agressor não dispõem de condições para superar o padrão relacional violento. (...) Esse padrão relacional inviabiliza até mesmo a compreensão de como começaram as agressões. Daí que nesses casos a percepção do padrão relacional torna-se, por vezes, mais importante que o esclarecimento da causalidade linear e dos motivos que permitem os episódios de violência. (Angelim \& Diniz, 2010, p. 402)

Essa reflexão teórica constitui a base para a apresentação de parte dos resultados da dissertação de mestrado do primeiro autor à luz da TDV e é detalhada e discutida na tese de doutorado do terceiro autor. Os dois trabalhos foram realizados sob a orientação da segunda autora e tiveram como eixo estruturante a necessidade de compreender como homens e mulheres nomeiam e percebem a própria história conjugal violenta. Serão detalhadas a seguir, o método da pesquisa e depois os seus resultados à luz da TDV.

\section{Método}

A experiência dos três autores com trabalhos junto a mulheres em situação de violência já havia evidenciado que essas mulheres tendem a minimizar ou mesmo negar suas experiências e suas dores. Tal constatação constituiu um desafio para a construção da pesquisa. Nesse contexto, foi adotada uma estratégia de pesquisa qualitativa a partir do uso de um estímulo indutor de reflexões, no caso o livro Mas ele diz que me ama: Grafic Novel de uma Relação Violenta, escrito por Rosalind B. Penfold (2005). Buscamos, na história de uma mulher vítima, escrita de forma criativa por meio da estratégia de quadrinhos, o elemento potencializador de reflexões sobre a experiência de violência conjugal de outras mulheres. A dimensão inovadora dessa estratégia justifica o caráter exploratório da pesquisa (Seidl de Moura \& Ferreira, 2005).

\section{Participantes}

Vinte mulheres em situação de violência conjugal participaram da pesquisa. Todas foram encaminhadas pela Justiça para acompanhamento psicossocial em Núcleos de Atendimento às Famílias e Autores de Violência Doméstica (NAFAVD) da Secretaria do Estado da Mulher (SEM) do Distrito Federal - Brasil.A idade das participantes variou entre 27 a 55 anos. Os níveis de escolaridade foram desde o ensino fundamental incompleto ao superior completo. A diversidade racial foi representada pela presença de mulheres negras, pardas, amarelas e brancas. As crenças religiosas foram a evangélica e a católica. O tempo de relacionamento compreendeu o intervalo de 2 a 35 anos. As mulheres relataram que estavam expostas às agressões por períodos muito distintos, desde 8 meses a 35 anos. Nove mulheres estavam separadas dos parceiros. A quantidade de filhos variou de 1 a 5 , duas mulheres relataram não ser mães. A renda variou de zero a quatro mil e quinhentos reais. Os dados demográficos corroboraram dados de outras pesquisas que mostram que a violência afeta mulheres de todas as idades, raças, crenças religiosas, e de diferentes níveis educacional e econômico. Esse resultado reitera que a violência é um fenômeno universal (Kruget al., 2002; Soares, 2005; Walker, 1999).

\section{Instrumentos e Materiais}

Os instrumentos utilizados foram o livro Mas ele diz que me ama (Penfold, 2005); um questionário criado pelos pesquisadores e o Formulário de Acolhimento de Mulheres do NAFAVD. Será apresentada a seguir uma breve descrição dos principais instrumentos.

Livro Mas Ele Diz que me Ama. A escolha metodológica pela utilização do livro Mas ele diz que me ama (Penfold, 2005) como material de pesquisa e instrumento eliciador de reflexões se deveu ao fato de ele narrar uma história conjugal violenta e abranger os principais elementos apontados na literatura como característicos dessas relações. O livro foi testado em atendimentos individuais e, uma vez constatado 
seu potencial clínico, tornou-se o principal instrumento dessa pesquisa.

O livro é de fácil compreensão, o que diferencia essa obra em relação a outras sobre o tema de violência. Ao mesmo tempo em que a história é narrada, a autora estabelece um diálogo com o/a leitor/a, o que facilita uma identificação desse/a leitor/a com a personagem. O livro relata a história da relação conjugal violenta vivida pela autora/ personagem e que perdurou por 10 anos. É protagonizado por Rosalind (Roz) - 35 anos, solteira e empresária - e Brian - viúvo e pai de quatro filhos. A narrativa revela como Roz passou de uma mulher forte, decidida, feliz e bemsucedida profissionalmente a esposa violentada (Penfold, 2005). Mostra desde a negação ao processo gradativo de conscientização, e aborda a ruptura do relacionamento e a retomada da vida da personagem após a separação. O livro é um sucesso editorial e foi publicado em 11 países, inclusive no Brasil (Guimarães, Silva, \& Maciel, 2007).

Questionário sobre o Livro Mas Ele Diz que me Ama. O questionário foi construído de acordo com os objetivos da pesquisa e é composto pelas seguintes questões:

1) Descreva qual foi o sentimento que você teve ao ler esse livro.

2) O que tem em comum na história do seu relacionamento e na história da personagem do livro - Roz?

3) O que tem de diferente em sua história?

4) Na folha em anexo, marque com um " $X$ " os pensamentos/sentimentos da Roz que são parecidos com os pensamentos que você teve.

5) Escolha três desses pensamentos que mais influenciaram sua história.

6) Além dos pensamentos apresentados pela Roz, você teve outros que te impediram de pedir ajuda, de quebrar o ciclo de violência ou de sair do relacionamento?

7) A Roz resumiu a história dela com o título: "Mas ele diz que me ama...". Qual seria o título da sua história?

8) Inspirada em sua história, complete o título do livro: Mas ele diz que me ama...

A questão 4 foi acompanhada por um material anexo - as 35 anestesias apresentadas pela autora em forma de quadrinhos nas duas contracapas do livro.

\section{Procedimentos}

A coleta de dados fez parte do processo grupal e foi realizada em dois encontros para cada grupo de mulheres um que estava no início e outro no final do acompanhamento psicossocial. As atividades desenvolvidas foram: $\mathbf{1}^{\mathbf{0}}$ encontro: (a) Leitura e assinatura do Termo de Consentimento Livre e Esclarecido; (b) Empréstimo de um exemplar do livro (Penfold, 2005); (c) Entrega do questionário sobre o livro e pedido de preenchimento individual do mesmo durante a semana. $2^{\circ}$ encontro: (a) Recolhimento do questionário preenchido; (b) Discussão em grupo com as mulheres sobre o livro e o questionário.
$\mathrm{O}$ intervalo de tempo entre o primeiro e o segundo encontro para cada grupo foi de uma semana. Os encontros foram facilitados pelo primeiro autor, na condição de psicólogo do NAFAVD, auxiliado por duas estagiárias. O segundo encontro teve duração aproximada de uma hora e meia para cada grupo. O procedimento de condução desse encontro foi padrão para os dois grupos: a dinâmica foi iniciada a partir de uma pergunta sobre a impressão geral das mulheres ao lerem o livro, seguida pela reflexão grupal de cada item do questionário.

Um nome foi atribuído a cada grupo, que foi escolhido entre os títulos dados pelas participantes para suas histórias, em resposta ao item oito do questionário. A ideia foi selecionar um nome que representasse melhor a postura de cada grupo. O Grupo Saindo do Cativeiro - GSC teve como participantes 10 mulheres que estavam chegando ao fim do acompanhamento psicossocial. Essas mulheres já estavam sendo capazes de ressignificar suas histórias e de tomar iniciativas para reconstruir as suas vidas. O Grupo Um Dia Serei Feliz - GSF nomeia o processo das 10 participantes que estavam no início da intervenção. O nome representa a esperança de mudança de sua realidade e do fim do sofrimento vivenciado pela vivência de violência conjugal.

\section{Análise dos Dados}

A natureza qualitativa da pesquisa nos levou a privilegiar a análise de conteúdo das respostas aos questionários preenchidos pelas participantes (Seidl de Moura \& Ferreira, 2005). O projeto de pesquisa foi submetido e aprovado pelo Comitê de Ética e Pesquisa do Instituto de Ciências Humanas da Universidade de Brasília.

\section{Resultados e Discussão}

As mulheres participantes mostraram boa adesão ao procedimento utilizado neste estudo. No GSC, todas as mulheres compareceram ao segundo encontro. No GSF, apenas uma participante não compareceu a esse encontro. Todas leram o livro e responderam o instrumento.

Este trabalho focou as duas últimas perguntas do questionário, que tiveram como objetivo conhecer como as participantes nomearam/intitularam e perceberam a própria história tendo como estímulo o título do livro Mas ele diz que me ama. As respostas apresentadas pelas participantes estão descritas na Tabela 1 .

A primeira coluna da tabela mostra o número indicativo de cada participante. A segunda apresenta a resposta ao item sete do questionário, que pedia às mulheres para nomearem a sua vivência com a seguinte instrução: "A Roz resumiu a história dela com o título Mas ele diz que me ama.... Qual seria o título da sua história?". As respostas ao item oito do instrumento estão descritas na terceira coluna da tabela, cujo comando foi: "Inspirada em sua história, complete a frase/ título do livro Mas ele diz que me ama...". A organização em uma única tabela permite a análise conjunta da resposta de uma mesma participante às perguntas sete e oito do 
Tabela 1. Respostas das participantes aos itens 7 e 8 do Questionário sobre o livro

\begin{tabular}{|c|c|c|}
\hline \multicolumn{3}{|c|}{ Grupo Saindo do Cativeiro - GSC } \\
\hline $\mathrm{P} 1$ & Você é a mulher da minha vida. & $\begin{array}{l}\text { Mas todo mundo que ama não bate, não é amor, e os que } \\
\text { dizem ama e mata, isso não é amor. }\end{array}$ \\
\hline $\mathrm{P} 2$ & Saindo do cativeiro. & Ele não ama nem a si mesmo. \\
\hline P3 & O desprezo de um homem. & E continua errando. \\
\hline P4 & Eu nunca fui feliz com ele. & $\begin{array}{l}\text { Ele nunca me diz que me ama, nunca falou, é sempre } \\
\text { caladão. }\end{array}$ \\
\hline P5 & $\begin{array}{l}\text { Teu silêncio e tua frieza me deixam em dúvidas do que } \\
\text { sentes por mim. }\end{array}$ & $\begin{array}{l}\text { E me engana, ele tem cara de pau. Falar não é fazer, fala que } \\
\text { ama e não ama e às vezes ama sem falar. }\end{array}$ \\
\hline P6 & $\begin{array}{l}\text { O homem que diz me amar me dirigiu a palavra nesses } \\
\text { termos... }\end{array}$ & Eu continuo dizendo que não ama. \\
\hline P7 & A decepção de uma sonhadora. & E por que as agressões? \\
\hline P8 & Mas suas atitudes não condizem. & Mas as atitudes dele não condizem. \\
\hline P9 & Apesar dos pesares, eu o amo tanto! & E por que me trai? Isso não é amor! \\
\hline $\mathrm{P} 10$ & Eu não conhecia o amor próprio... & Não quero nem saber, eu vou me amar mais. \\
\hline \multicolumn{3}{|c|}{ Grupo Um Dia Serei Feliz - GSF } \\
\hline P11 & Mas ele diz não consigo viver sem você. & Porque não faz nada para mudar. \\
\hline $\mathrm{P} 12$ & Deus é fiel. & Mas não se esforça para amar. \\
\hline P13 & Um dia serei feliz. & Mas ele quer me matar. \\
\hline P14 & A insistência dele foi em vão. & Mas não demonstra. \\
\hline $\mathrm{P} 15$ & Dê-me mais uma chance, a última! & Mas não como antes. Não como eu o amo. \\
\hline P16 & Amor e ódio. & Mas me faz sofrer. \\
\hline P17 & $\begin{array}{l}\text { Por que se chama de amor se traz tantas dúvidas, medos e } \\
\text { inseguranças. Será mesmo amor? }\end{array}$ & $\begin{array}{l}\text { Mas que amor é esse que traz tantas questões e tantas } \\
\text { dúvidas. }\end{array}$ \\
\hline P18 & Ele não me ama. & Mas não me merece. \\
\hline P19 & Ele merece uma chance pra mudar. & $\begin{array}{l}\text { E que nunca ninguém me ama mais do que ele (perda de } \\
\text { tempo!). }\end{array}$ \\
\hline
\end{tabular}

questionário. Esse formato possibilita a compreensão mais clara dos critérios do duplo-vínculo.

A análise das respostas foi feita com base no entendimento de que a resposta à questão sete do instrumento possibilitou às participantes exporem as anestesias que as aprisionavam ou aprisionam à relação conjugal. A resposta ao item oito permitiu a constatação de que há algo errado no relacionamento: estimulada pela palavra "mas" do título do livro. Ao juntar as duas respostas, foi possível fazer uma reflexão sobre o paradoxo entre as anestesias apresentadas pelas mulheres e a percepção da realidade violenta da conjugalidade. As respostas/percepções das mulheres acerca de suas histórias foram analisadas à luz da TDV.

A nomeação/intitulação da própria história por parte das mulheres revelou os paradoxos da presença da violência na relação. A partir da análise desses títulos foram identificadas quatro categorias: (a) Ambiguidade de sentimentos; (b) As promessas do parceiro; (c) A constatação da realidade violenta; e (d) Perspectiva de uma nova vida. Essas categorias serão apresentadas e problematizadas a seguir.

\section{Do Título do Livro aos Paradoxos das Histórias Reais}

A análise conjunta das respostas aos dois últimos itens do questionário permite refletir sobre os paradoxos da ambiguidade de sentimentos e da violência. Esses paradoxos são expostos nos trechos a seguir:

P5: "Teu silêncio e tua frieza me deixam em dúvidas do que sentes por mim" e "E me engana, ele tem cara de pau (...) fala que ama e não ama, às vezes ama sem falar"; P6: "O homem que diz me amar me dirigiu a palavra nesses termos..." $e$ "Eu continuo dizendo que não ama"; P9: "Apesar dos pesares, eu o amo tanto!" e "E por que me trai? Isso não é amor!"; P12: "Deus é fiel" " "Mas não se esforça para amar"; P16: "Amor e ódio" e "Mas me faz sofrer"; P17: "Por que se chama de amor se traz tantas dúvidas, medos e inseguranças. Será mesmo amor?" e "Mas que amor é esse que traz tantas dúvidas".

A resposta de P12 "Deus é fiel" pode parecer vaga. Entretanto, a análise desse título em conjunto com o seu relato verbal: "Deus é fiel! Eu tenho fé em Deus, que vai melhorar, eu te garanto", revela a ambiguidade de sentimentos entre sua esperança de mudança da relação e a constatação de que o parceiro não se esforça para mudar.

O paradoxo entre amor e violência tende a deixar as mulheres extremamente confusas sobre o vínculo com seus parceiros (Angelim \& Diniz, 2010). Essa característica foi apresentada pelas mulheres dos dois grupos. A ambiguidade favorece a reafirmação do relacionamento, e, diante da dúvida, prevalece a tendência em continuar na relação conjugal. Essa reafirmação reforça a ilusão de que a violência 
não tem solução e contribui para a sensação de que não há como interrompê-la (Walker, 1999).

A relação dos cônjuges vai muito além da violência - existe afeto, agressão, amor, ódio, respeito, desprezo, confiança, medo, etc. (Aguiar, 2009; Safiotti, 1999). Os parceiros podem ser brincalhões, amorosos, atenciosos, sensíveis, excitantes e afetuosos em diversos momentos, mas também são coercitivos, controladores e agressivos (Aguiar, 2009; Walker, 1999). Essa dinâmica paradoxal ajuda a compreender a disposição das mulheres para punir e, ao mesmo tempo, voltar atrás e querer cuidar do parceiro agressor quando recorrem à Justiça.

O fato de o parceiro ser uma pessoa de intenso valor afetivo favorece a instalação de uma dinâmica de submissão da mulher em busca do reconhecimento da pessoa amada (Angelim \& Diniz, 2010). A dúvida gerada pela ambiguidade favorece a manutenção da relação, correspondendo à estereotipia esperada do comportamento feminino, fator que dificulta a reflexão sobre sua condição subjetiva. Essa dinâmica reforça ainda mais a dependência da mulher ao lócus conjugal e familiar. A dinâmica duplo-vincular não permite alternativas fora da relação. Surge a dificuldade em romper esse padrão e a tendência da violência em se perpetuar e se agravar indefinidamente (Beauvoir, 1967; Angelim, 2009; Angelim \& Diniz, 2010).

Várias mulheres compreenderam a existência de paradoxos entre as promessas do parceiro e a presença de violência na relação,que ficam evidentes nos exemplos a seguir:

P1: "Você é a mulher da minha vida" e "Mas todo mundo que ama não bate, não é amor"; P11: "Mas ele diz não consigo viver sem você" e "Porque não faz nada para mudar"; P15: "Dê-me mais uma chance, a última!" " Mas não como antes. Não como eu o amo"; P19: "Ele merece uma chance pra mudar" e "E que nunca ninguém me ama mais do que ele (perda de tempo!)”.

As promessas feitas pelo parceiro formam uma poderosa anestesia e aprisionam as mulheres. Atuam como reforçadores de uma ilusão de que um dia o parceiro e a relação irão melhorar ou voltar a ser como antes (Guimarães, 2009; Ravazzola, 1997; Walker, 1999). Essas promessas têm mais peso que a própria constatação da violência e podem influenciar ainda a construção da própria identidade (McGoldrick, 1994).

A própria autora/personagem do livro Mas ele diz que me ama evidencia o paradoxo entre a promessa do parceiro e as violências cometidas: "fiquei apegada às promessas de Brian em vez de confiar naquilo que eu via e nas minhas próprias experiências. Minha negação e minha vergonha me mantiveram ao lado dele por dez anos" (Penfold, 2005, p. xiii).

Algumas participantes foram capazes de superar a ambiguidade de sentimentos e a armadilha das promessas do parceiro. Elas perceberam a inadequação do paradoxo entre amor/violência na relação. Nesses casos, as mulheres apresentaram a constatação da realidade violenta nas duas respostas aos últimos itens do questionário:

P3: "O desprezo de um homem" e "E continua errando"; P4:

"Eu nunca fui feliz com ele" e "Ele nunca me diz que me ama, nunca falou, é sempre caladão”; P7: "A decepção de uma sonhadora" e "E por que as agressões?"; P8: "Mas suas atitudes não condizem" e "Mas as atitudes dele não condizem"; P14:

"A insistência dele foi em vão" e "Mas não demonstra"; P18:

"Ele não me ama" e "Mas não me merece".

Esse processo de conscientização esteve presente nos dois grupos de mulheres, apesar de ter se destacado no GSC. A estratégia utilizada permitiu às participantes iniciarem o processo de reflexão acerca das mensagens paradoxais e desafiar/rever o valor de sobrevivência em relação ao parceiro agressor (Angelim \& Diniz, 2010).

A palavra "mas" - do item 8 do questionário - permitiu confrontar diretamente suas anestesias relacionais (Ravazzola, 1997). Elas questionaram o paradoxo entre o amor que o parceiro afirmava sentir e a violência que ele praticava (Angelim \& Diniz, 2010). O exercício de dar continuidade ao título do livro pôde ajudá-las a se posicionaram acercada existência dessa contradição.

Outra característica que se destaca nos títulos apresentados pelas participantes é a constatação da contradição entre a perspectiva de uma nova vida e a violência vivenciada. As respostas abaixo mostram que elas passaram a desafiar a possibilidade de mudança do parceiro ou da relação:

P2: "Saindo do cativeiro" e "Ele não ama nem a si mesmo";

P10: "Eu não conhecia o amor próprio..." e "Não quero nem

saber, eu vou me amar mais"; P13: "Um dia serei feliz" e "Mas ele quer me matar".

A expectativa de poder construir uma nova vida foi apresentada por três participantes - duas do grupo GSC e uma do GSF. Elas afirmam o desejo de continuar suas vidas sem a violência ao escolherem como títulos: "não quero nem saber, eu vou me amar mais", "saindo do cativeiro" e "um dia serei feliz". Os dois primeiros relatos são de participantes que estão separadas de seus parceiros e pretendem reconstruir as suas histórias. Uma delas afirma não depender do sentimento dele para reconstruir a sua vida, o que indica que ela pode ter iniciado o processo de reflexão para questionar a primeira condição da TDV - valor de sobrevivência. Ela mostrou estar no caminho de resgatar a sua autoestima: "não quero nem saber, eu vou me amar mais".

A terceira participante ainda morava com o cônjuge. Sua fala pode significar a esperança de mudança dentro ou fora da relação e evidenciou o extremo paradoxo entre amor/violência: "Mas ele diz que me ama...mas ele quer me matar". Ela tem consciência da possibilidade do relacionamento conjugal chegar a um fim trágico: a morte de um dos cônjuges, provavelmente a dela (Kruget et al., 2002; Waiselfisz, 2012). Outra participante também apontou essa possibilidade de feminicídio: "mas todo mundo que ama não bate, não é amor, e os que dizem ama e mata, isso não é amor”.

\section{Considerações Finais}

Os critérios de duplo-vínculo discutidos e aplicados neste trabalho ajudam a compreender como mulheres inseridas em relacionamentos violentos estruturados pela dinâmica duplovincular ficam sem recursos para avaliar o risco da violência (Angelim, 2009). O desconhecimento da dinâmica duplovincular nessas relações aponta para o total descrédito a que a mulher é submetida, sobretudo quando ela retorna diversas vezes para a relação. Familiares, amigos e, muitas vezes, até 
os próprios profissionais - responsáveis por ajudarem essas mulheres - reforçam inadvertidamente a insegurança e o medo de uma vida sem o parceiro. Contribuem, assim, para a perpetuação do relacionamento estruturado pela violência (Guimarães, 2009; Ravazzola, 1997).

Mulheres relatam ouvir em audiências: "Você têm certeza de que quer denunciar/continuar o processo?", "Você sabe o que pode acontecer com ele?"; "Você tem certeza de que quer processar o pai de seus filhos?". A ênfase colocada na palavra "certeza" alimentam as dúvidas de cada mulher e, é frequentemente eficaz em demovê-la de seu propósito de mudança na relação ou de pedido de ajuda a terceiros (Guimarães, 2009).

O conhecimento da TDV permite entender como muitas mulheres ficam sem condições de mudar o padrão conjugal ou sair da relação sem a ajuda de outras pessoas (Angelim \& Diniz, 2010; Ravazzola, 1997). A sua correta aplicação pode trazer diversos benefícios: (a) ajudar no entendimento da dificuldade vivenciada pelas mulheres em definirem um claro pedido de ajuda à Justiça; (b) oferecer oportunidade de reflexão diferenciada e permitir, assim, mais autonomia e segurança para as vítimas; (c) evitar que o arquivamento do processo se configure como mais uma conduta duplovincular; (d) estabelecer critérios para avaliar se as vítimas dispõem de condições de reflexão para avaliarem os riscos da violência (Angelim \& Diniz, 2010).

A TDV mostrou ser mais um valioso instrumento para compreensão e intervenção em casos de violência conjugal. Configura-se como um meio de avaliação de risco relevante - inclusive em audiências interdisciplinares (Macedo et al., 2012). Os profissionais podem ter na TDV uma ferramenta eficaz e eficiente para identificar padrões de relacionamento estruturados pela dinâmica duplo-vincular, cujo padrão tende a se perpetuar e oferecer mais risco às vítimas.

Toda proposta metodológica possui limitações. A eficácia desta pesquisa-intervenção depende da leitura de um livro. A exigência da capacidade de leitura e escrita por parte das participantes pode ser um empecilho em contextos de pobreza. Não há como garantir que as participantes de fato leiam o livro durante a semana. Essas dificuldades podem ser contornadas através do incentivo às participantes para pedirem a terceiros - familiares, amigos/as, etc. A história pode também ser lida no próprio grupo de mulheres - assim a pessoa que não sabe ler, pode ouvir e acompanhar a leitura através das ilustrações.

$\mathrm{O}$ aprimoramento dessa proposta de pesquisa e intervenção merece atenção. Pode-se ampliar essa pesquisa para uma amostra maior de mulheres participantes. Outra pesquisa-intervenção que merece atenção é usar o livro e fazer um estudo para discutir a percepção dos homens a partir da narrativa da mulher vítima e para identificar elementos da TDV junto aos homens "agressores".

A estratégia metodológica utilizada - leitura do livro e preenchimento do questionário associados à reflexão grupal - pode ser uma forma de intervenção eficaz. Ela tende a favorecer a quebra da terceira condição de duplo-vínculo: a impossibilidade de sair e/ou de refletir sobre a relação. Contribui para quebrar o silêncio e o segredo em torno da violência vivida (Diniz \& Pondaag, 2006; Pondaag, 2009). Esse recurso também pode auxiliar as mulheres a questionarem a segunda condição do duplo-vínculo: o paradoxo entre o afeto prometido pelo parceiro e a violência praticada por ele.

\section{Referências}

Aguiar, L. H. M. (2009). Gênero e masculinidades: Follow-up de uma intervenção com homens autores de violência conjugal. Dissertação de Mestrado, Instituto de Psicologia, Universidade de Brasília, Brasília.

Alves, S. L. B., \& Diniz, N. M. F. (2005). Eu digo não, ela diz sim: A violência conjugal no discurso masculino. Revista Brasileira de Enfermagem, 58(4), 387-392.

Angelim, F.P. (2009). Mulheres vitimas de violência: Dilemas entre a busca da intervenção do Estado e a tomada de consciência (Tese de doutorado). Instituto de Psicologia, Universidade de Brasília, Brasília.

Angelim, F. P., \& Diniz, G. R. S. (2010). A Teoria do DuploVínculo como referencial teórico para intervenções em casos de violência contra mulheres. Em I. Ghesti-Galvão \& E.C.B Roque (Orgs.), Aplicação da lei em uma perspectiva interprofissional: Direito, psicologia, psiquiatria, serviço social e ciências sociais na prática jurisdicional. (pp. 397 412). Brasília: Editora Lumen Juris.

Bateson, G., Jackson, D. D., Haley, J., \& Weakland, J. H. (1956). Toward a theory of schizophrenia. Behavioral Science, 1(4), 251-254

Beauvoir, S. (1967) O segundo sexo: A experiência vivida (2a ed.). São Paulo: Difusão.

Diniz, G. R.S . (2011). Conjugalidade e violência: Reflexões sob uma ótica de gênero. Em Terezinha Féres-Carneiro (Org.), Casal e família: Conjugalidade, parentalidade e psicoterapia (pp. 11-26). São Paulo: Casa do Psicólogo.

Diniz, G. R. S., \& Pondaag, M. C. M. (2006). A face oculta da violência contra a mulher: $O$ silêncio como estratégia de sobrevivência. Em A. M. O. Almeida, M. F .S. Santos, G. R. S. Diniz \& Z. A. Trindade (Orgs.), Violência, Exclusão Social e Desenvolvimento Humano: Estudos em Representações Sociais. (pp. 233-259). Brasília: Editora Universidade de Brasília - EDUnB.

Guimarães, F. (2009). "Mas ele diz que me ama...": Impacto da história de uma vítima na vivência de violência conjugal de outras mulheres (Dissertação de mestrado). Universidade de Brasília, Brasília.

Guimarães, F., Silva, E. C., \& Maciel, S. A. B (2007). Resenha: "Mas ele diz que me ama...": Cegueira relacional e violência conjugal. Psicologia: Teoria e Pesquisa, 23(4), 481-482.

Hamilton, L., \& Armstrong, E. A. (2009). Gendered sexuality in young adulthood: Double binds and flawed options. Gender \& Society, 23(5), 589-616.

Krug, E. G., Dahlberg, L. L., Mercy, J. A., Zwi, A. B., \& Lozano, R. (2002). Relatório mundial sobre violência e saúde. Geneva: Organização Mundial de Saúde. 
Macedo, D., Guimarães, F., Tusi, M., Guimarães, R., Chaves, R.,\& Ramos, T. (2012). Audiências interdisciplinares e violência contra a mulher: Intervenções psicossociais no âmbito do TJDFT. Em M. Lobão, E. Resende, E. C. B. Roque \& V. Brito (Orgs.), Conexões: Teoria e Prática do Trabalho em Redes na Secretaria Psicossocial Judiciária do TJDFT (pp. 13-32). Brasília: Lúmens Juris.

Macedo, D. S. (2013). Exercícios para Liberação da Tensão e do Trauma (TRE): Aplicação a situações de violência conjugal. (Dissertação de Mestrado). Universidade de Brasília, Brasília.

Magalhães, N. T. (2011). Gênero e violência conjugal: Olhares de um sistema de justiça especializado (Dissertação de Mestrado), Universidade de Brasília, Brasília.

Mahmoud, V. M. (2003). Os duplos vínculos do racismo (pp. 293-307). Em M. McGoldrick (Org.), Novas abordagens da terapia familiar: Raça, cultura e gênero na prática clínica. São Paulo: Roca.

McGoldrick, M. (1994). As mulheres e o ciclo de vida familiar. Em B. Carter\& M. McGoldrick (Orgs.), O ciclo de vida familiar: Uma abordagem para a terapia familiar. Porto Alegre: Artes Médicas.

Knickmeyer, N., Levitt, H. M., Horne, S. G., \& Bayer, G. (2004). Re spondingtomixedmessagesanddouble binds: Religious oriented coping strategies of Christian battered women. Journal of Religion and Abuse, 5, 55-82.
Penfold, R. B. (2006). Mas ele diz que me ama: Graphic novel de uma relação violenta (D. Pelizzari, trad.). Rio de Janeiro: Ediouro.

Pondaag, M. C. M. (2009). Sentidos da violência conjugal: A perspectiva de casais (Tese de Doutorado). Universidade de Brasília, Brasília.

Ravazzola, M. C. (1997). Historias infames: Los maltratos en las relaciones. Buenos Aires: Paidós.

Saffioti, H. I. B. (1999). Já se mete a colher em briga de marido e mulher. São Paulo em Perspectiva, 13(4), 82-91.

Seidl de Moura, M. L., \& Ferreira, M. C. (2005). Projetos de Pesquisa: Elaboração, redação e apresentação. Rio de Janeiro, RJ: EDUERJ.

Soares, B. M. (2005). Enfrentando a violência contra a mulher: Orientações práticas para profissionais e voluntários(as). Brasília: SPM.

Teixeira, A. B. (2009). Nunca você sem mim: Homicidas-suicidas nas relações afetivo-conjugais. São Paulo: Annablume.

Walker, L. E. A. (1999). The battered woman syndrome. (2ºd.). Nova York: Springer Publishing Company.

Waiselfisz, J. J. (2012). Mapa da Violência 2012. Os novos padrões da violência homicida no Brasil - Caderno Complementar 1: Homicídios de Mulheres no Brasil. São Paulo: Instituto Sangari.

Watzlawick, P., Beavin, J.H., \& Jackson, D. D. (1995). Pragmática da comunicação humana. São Paulo: Cutrix. (Original publicado em 1967) 